\title{
La paradoja del liberalismo y la deuda de los Estados liberales*
}

Christianne Silva Vasconcellos**

Recibido: mayo de 2015

Aprobado agosto de 2015

Resumen: Aquí analizaremos la paradoja de la política liberal de abolición de la esclavitud, gradual e indemnizatoria, que fue adoptada en Latinoamérica y en el Caribe, y que tuteló el derecho patrimonial de los propietarios esclavistas en detrimento de los derechos humanos de las personas esclavizadas. Trataremos sobre los argumentos teóricos del liberalismo para mantener la esclavitud en los Estados liberales y unas justificativas para proceder a una abolición gradual de la esclavitud con indemnización para los propietarios esclavista, excluyendo cualquier tipo de compensación o reparación hacia las personas esclavizadas. Sugeriremos que esta fue una omisión legislativa discriminatoria producida en el siglo XIX sigue generando efectos hasta los días actuales y se configura como manifestación de una injusticia histórica, por parte de los Estados liberales independientes.

Palabras clave: Abolición de la esclavitud, Latinoamérica, Caribe, Indemnización, propietarios esclavistas, derechos humanos, personas esclavizadas.

\footnotetext{
* Este texto es una parte del capítulo 3 de mi tesis doctoral en elaboración en la Facultad de Derecho de la Universidad Nacional de Colombia, bajo la dirección del Dr. Gregorio Mesa Cuadros. Fue escrito para participación en el V Seminario Internacional de Historia Económica promovido por la Universidad de Cartagena, Colombia Agosto 11, 12 y 13 de 2015, Mesa 6 Historia Económica y Social.

** Magister en Historia Social, Universidade Federal da Bahia (UFBA), Doctoranda en Derecho Universidad Nacional de Colombia (UN). Integrante del Grupo de Investigaciones de Derechos Colectivos y Ambientales (GIDCA-UN).

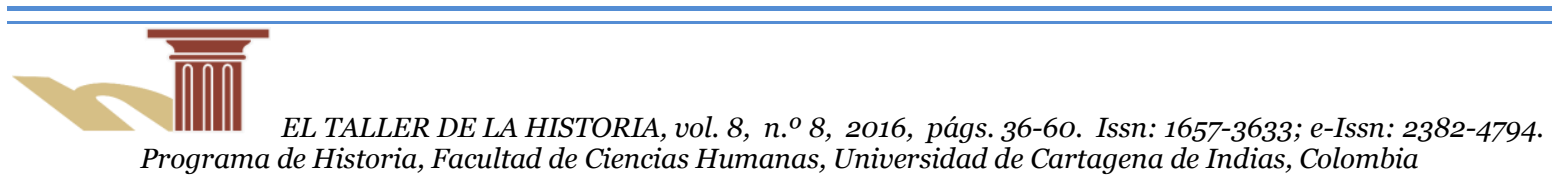




\begin{abstract}
This article analyses a paradox in liberal policies of abolition of slavery which were adopted in Latin America and Caribbean countries after political independence. Those policies were gradual so to allow compensation for slave-owners and protect their patrimonial rights, although at the expense of Africans and Afro-descents' human rights. We highlight the theoretical justifications used by liberals to proceed on a gradual abolition, so the State would be able to pay compensation to slave-owners, while omitted any kind of compensation or reparation to enslaved population. From a legal perspective, we suggest that laws directed to apply gradual abolition of slavery made a legislative omission, to the point that they continue producing sociological effects at present day. That way, Latin-American abolition laws are an evidence of historical injustice committed by liberal states toward African and AfricanLatin-American populations, which must be corrected through reparation toward African and African descents.
\end{abstract}

Keywords: Latin America, Caribbean, Liberalism, Reparation, Gradual abolition to compensate enslaved owners.

\title{
Introducción
}

En este texto analizaremos la paradoja de la política liberal de abolición de la esclavitud, gradual e indemnizatoria, que fue adoptada en Latinoamérica y en el Caribe, y que tuteló el derecho patrimonial de los propietarios esclavistas en detrimento de los derechos humanos de las personas esclavizadas. Contextualizando el caso a tratar, en el momento de las independencias Latinoamericanas existían dos alternativas legislativas para hacer frente a la institución colonial de la esclavitud: la abolición gradual y regional desarrollada en Estados Unidos desde 1776; y la abolición inmediata realizada por Haití a partir de la declaración de su independencia en 1801 y en la Constitución de 1805. Pero, exceptuando a Haití, todas las demás naciones en el continente siguieron el modelo de la abolición gradual, enfatizando la garantía de indemnización a los propietarios esclavistas, lo que fue previsto en las constituciones liberales diseñadas en ese periodo y en el Derecho estatal.

En ese contexto, ni siquiera Haití quedó eximida del pago indemnizatorio a los esclavistas y a los colonialistas pues, en 1825, la monarquía liberal francesa impuso al Estado independiente de Haití la asombrosa suma de 150 millones de francos 
oro para el reconocimiento de su independencia. ${ }^{1}$ Asimismo entre los años de 1830 y 1860, la abolición de la esclavitud en el Caribe fue realizada sólo después de que se garantizara la indemnización para los propietarios esclavistas. En 1833 el parlamento liberal británico autorizó el pago en efectivo a los esclavistas con dinero proveniente del presupuesto público, modelo que fue seguido por los demás países colonizadores como Holanda y Francia. ${ }^{2}$

Mientras tanto, en Latinoamérica la abolición gradual e indemnizatoria de la esclavitud empezó con la Ley de libertad de vientres o partos adoptada en países como Chile (1811), Argentina (1813), Colombia (1814), Perú (1823) o Brasil (1871). Una persona que nacía bajo la ley de vientre libre no tenía la condición jurídica de esclavo tampoco de libre. La libertad llegaría después de varios años de trabajo esclavo, prestado al propietario de la madre; lo que correspondería a la compensación por trabajo al esclavista. La indemnización pecuniaria fue ejecutada a través de los fondos de manumisión o emancipación, que era un sistema de impuestos creado por el Estado para financiar tal pago, y fue asumido como una deuda pública. ${ }^{3}$ Además, para la operatividad del impuesto de los fondos de manumisión fue desarrollada una burocracia estatal que definía el precio de la persona y de quiénes serían libertados. La indemnización a los propietarios esclavistas fue justificada en el código medieval de las Siete Partidas 4 y en las garantías que gozaba el derecho a la propiedad en el marco del naciente liberalismo.

De acuerdo con el jurista italiano Luigi Ferrajoli hubo un equívoco insólito en la génesis del liberalismo, cuando los teóricos liberales introdujeron el derecho a la propiedad en la categoría de derechos humanos como la vida, la libertad, la igualdad

\footnotetext{
${ }^{1}$ H. M. Beckles, (1991). "An Unnatural and Dangerous Independence': The Haitian Revolution and the Political Sociology of Caribbean Slavery". The Journal of Caribbean History, 25(1), 160; B. Macintyre, (2010), "The fault line in Haiti runs straight to France". The Sunday Times, 21.

${ }^{2}$ Stanley Engerman (2008). “Emancipation schemes: different ways of ending slavery”.In. Slave Systems: Ancient and Modern, (265-82), p.275-276

3 George Reid Andrews, (2007), "Las guerras por la libertad 1810-189o". En Afro-Latinoamérica 180o-200o. Madrid, Iberoamericana, Frankfurt am Main, Vervuert, p. 115-116.

4 Alfonso X El Sabio. Las siete partidas (1256-1265). Selección, prólogos y notas de Francisco López Estrada y María López García-Berdoy. Madrid: Editorial Castalia, 1992.
} 
y la dignidad5. Como destaca el autor, la concepción de la propiedad como un derecho fundamental fue teorizada por John Locke y fue introducida en las declaraciones de derecho humanos proclamadas por los gobiernos revolucionarios liberales, tales como Inglaterra en el Bill of Rights de 1689, en Francia en la Declaración de 1789, que consagró el "derecho sagrado e inviolable de la propiedad" (art.17), así como en la declaración de independencia de Estados Unidos de 1776. Desde entonces, el derecho a la propiedad se deslizó del derecho patrimonial hacia el derecho civil. Como señaló Thomas Marshall en 1950, citado por Ferrajoli, ésta fue una operación que se originó en la génesis del liberalismo, la cual condicionó, hasta los días actuales, tanto la teoría de los derechos, como el Estado de derecho,

En su base hay un equívoco, debido al carácter polisémico de la noción de "derecho de propiedad", con el que se entiende - tanto en Locke como en Marshall - al mismo tiempo el derecho a ser propietario y a disponer de los propios derechos de propiedad, que es un aspecto de la capacidad jurídica y de la capacidad de obrar reconducible sin más a la clase de los derechos civiles, y el concreto derecho de propiedad sobre este o aquel bien. ${ }^{6}$

Esta confusión en el pensamiento liberal, escribe Ferrajoli, "además de ser fuente de un grave equívoco teórico", ha sido responsable por una contradictoria operación jurídica: la valorización de la propiedad privada simultánea a la desvalorización de las libertades fundamentales. ${ }^{7}$ De tal manera, contrario a ser una alternativa libertaria que planteara la aplicación universal de los principios de igualdad y libertad en un régimen de democracia participativa y de derechos fundamentales, la ideología del liberalismo sirvió al objetivo de construir justificativas teóricas y prácticas para la defensa de la propiedad privada de la burguesía y de la oligarquía terrateniente, tanto en Europa como en América. Para citar un ejemplo de este contexto histórico, el historiador Eric Williams refirió un caso ocurrido en 1783, durante la travesía transatlántica de un buque inglés,

Debido a la falta de agua, el capitán había arrojado al agua 132 personas y los propietarios presentaron una demanda alegando que la pérdida de los esclavos

\footnotetext{
5 Ferrajoli, Luigi (1999). Derechos y garantías. La ley del más débil. Madrid, Editorial Trotta, p.45

${ }^{6}$ Ferrajoli, 1999, Derechos y garantías, p.45.

7 Ferrajoli 1999, p. 45.
} 
se ajustaba a la cláusula de las normas que aseguraban contra los "peligros del mar". [...] Fueron adjudicadas indemnizaciones de treinta libras por cada esclavo y la idea de que el capitán de la tripulación debería ser procesado por homicidio masivo, no entró ni por un momento en la cabeza de ningún humanitario. ${ }^{8}$

No resta duda que este proceso de valorización de la propiedad privada junto con el desarrollo normativo dirigido a su protección, ocurrió en la misma medida de la desvalorización de la humanidad y de los derechos humanos de las personas esclavizadas, tal como lo demostraron la expedición de normas que vulneraban los derechos fundamentales de estas personas, en especial, el de la igualdad. En Latinoamérica, las normatividades que prolongaron la trata de personas y la esclavitud perpetua después de las independencias, son evidencias de esta concepción de propiedad desarrollada por el Estado liberal de derecho. De hecho, en esa normatividad, la protección a la persona esclavizada estuvo dirigida no a la protección de su humanidad, sino a la preservación de la propiedad del esclavista. La figura jurídica del esclavo fue objeto de la ley privada, civil y penal, y en todas ellas los derechos de las personas esclavizadas fueron vulnerados.

\section{Esclavismo liberal la gran paradoja del liberalismo}

El negocio criminal de la trata transatlántica de personas africanas, el régimen de esclavitud perpetua, el confisco y expropiación de tierras a través del sistema cristiano colonial esclavista fue la base económica de las monarquías católicas absolutistas en el marco de la acumulación primitiva del capital entre los siglos XV y XVIII. En el siglo XV la esclavización de personas africanas fue considerada una sanción justa contra los prisioneros de las guerras religiosas llevadas a cabo en el norte de África.

Cuando contaban con casi dos siglos de existencia y desarrollo, surgieron los primeros paradigmas liberales que proponían romper con el gobierno del absolutismo monárquico y asumir el negocio colonial esclavista sin la injerencia de la co-

\footnotetext{
8 Eric E Williams (1944). Capitalismo y esclavitud. Habana, Editorial La Habana, Ciencias Sociales,
} 1964, p.85 
rona. Inicialmente, para justificar la esclavitud de las personas africanas, los gobiernos revolucionarios liberales mantuvieron la justificativa absolutista basada en el modelo de la servidumbre y la esclavitud legalizada en las Siete Partidas, así como en el paradigma del cautiverio derivado de la guerra justa. De acuerdo con la doctrina agustiniana, la esclavitud perpetua era un indulto que eximía de la muerte al prisionero de guerra.

La justificativa de la guerra religiosa y esclavización perpetua de los prisioneros de guerra fue utilizada durante las campañas militares que invadieron toda la costa africana con el objetivo de secuestrar y traficar personas para ser esclavizadas en Europa y en América. En el documento Brevísima relación de la destrucción de África escrito entre 1540-1554 y publicado en la Historia de las Indias, el fray dominico Bartolomé de las Casas criticó el uso del argumento religioso para justificar la esclavización de las personas capturadas en África. Según el autor, esta práctica infame era fruto de la codicia de los portugueses y no podía ser justificada por las guerras religiosas. Bartolomé de las Casas describió los asaltos a las islas atlánticas y a los reinos africanos y condenó como injusta y corrupta la guerra y la captura de los habitantes de las islas Canarias, Cabo Verde, Azores, Río del Oro, Arguin, Congo y Cabo de Bojador, argumentando que muchas de estas sociedades no estaban involucradas en las guerras religiosas de reconquista9.

La documentación portuguesa de la trata transatlántica trabajada por el historiador A.C. de C.M. Saunders corrobora la denuncia de Las Casas de que los primeros asaltos en territorio africano fueron dirigidos para generar un lucro comercial bajo el sinuoso argumento de que eran parte de las guerras religiosas. Saunders trabajó con fuentes que demuestran que antes de conocer el contorno del continente

9Según Las Casas, "Y esta es la ceguedad, como arriba tocamos, que ha caído en los cristianos mundanos, creer que por ser infieles los que no son baptizados, luego les es lícito salteallos, roballos, captivallos y matallos; ciertamente, aunque aquélos eran moros, no los habían de captivar, ni robar, ni altear, pues no eran de los que por las partes de la Berberia y Levante infestan y hacen daño a la cristandad, y eran otras gentes éstas, diferentes de aquéllas, en provincias y en condición muy distantes; y bastaba no tener nuestras tierras, como no lo eran las de Etiopia, ni hacernos guerra, ni serles posible hacerla, ni sernos en cargo de otra manera, para ser aquellos portogueses, de necesidad de salvarse, obligados a no guerreallos, ni salteallos, ni hacelles daño alguno, sino a tractar con ellos pacíficamente, dándoles ejemplo de cristandad”. Bartolomé de las Casas (1567). Brevisima relacion de la destruccion de Africa: preludio de la Destrucción de Indias: primera defensa de los guanches y negros contra su esclavización. Editorial San Esteban, 1989, p.785. 
africano y verificar la supuesta infidelidad religiosa de sus habitantes, los portugueses ya venían estructurando un sistema estatal para el secuestro, el tráfico y la esclavización de personas africanas con fines únicamente comerciales. ${ }^{10}$ Luego, las deportaciones masivas de personas africanas hacia las distintas colonias en América y Caribe, fue el resultado de la expansión y de la consolidación de las redes del tráfico humano.

Aun así en el Tratado sobre el gobierno civil (1690) escrito y publicado en el marco de la Revolución Gloriosa (1688), John Locke justificó la esclavitud absoluta y perpetua, con el mismo argumento medieval de tratarse de personas aprisionadas en la guerra justa,

[...] hay otra clase de siervos a los que damos el nombre particular de esclavos. Estos, al haber sido capturados en una guerra justa, están por derecho de naturaleza sometidos al dominio absoluto y arbitrario de sus amos. Cómo digo, estos hombres, habiendo renunciado a sus vidas y, junto con ellas, a sus libertades; y habiendo perdido sus posesiones al pasar a un estado de esclavitud que no los capacita para tener propiedad alguna, no pueden ser considerados como parte de la sociedad civil del país, cuyo fin principal es la preservación de la propiedad. ${ }^{11}$

Para Locke, la esclavitud derivada de la supuesta guerra justa, no debía regirse dentro de los límites de un contrato y la persona esclavizada no podría poseer propiedad alguna, pues no era considerada como parte de la sociedad civil que tenía por finalidad esencial la preservación de la propiedad. En los Tratados Locke legitimó el gobierno liberal de Inglaterra y la opción por mantener la colonización de la tierra, la trata transatlántica y esclavización de personas africanas, como pilares económicos legítimos del gobierno liberal. Asimismo defendió asiduamente la existencia del régimen esclavista y sostuvo que la esclavización de los "pueblos bárbaros [...] no ofende el derecho natural". ${ }^{12}$ De hecho Locke era accionista de la compañía escla-

10 Saunders, A.C.C.M. (1994). Historia social dos escravos e libertos negros em Portugal (14411555.). Lisboa, Imprensa Nacional Casa da Moeda, 1994, p. 26.

${ }^{11}$ John Locke (1690). Segundo Tratado sobre el Gobierno Civil. Un ensayo acerca del verdadero origen, alcance y fin del Gobierno Civil. London, Aronsham Churchill, at the black swan in AveMary-Lane, by Amen-Corner, Capítulo. 5 de la propiedad, $§ 85$.

${ }^{12}$ Locke, 1689, Capitulo 4 de la Esclavitud, top.22. 
vista Royal African Company y secretario (entre 1673-74) de la organización colonialista del Council of Trade and Plantations, lo que demuestra que en la teoría y en la práctica el padre del liberalismo, lucró con el colonialismo y la esclavización humana a que defendía. ${ }^{13}$

Su teoría fue aplicada en la carta fundamental de la colonia de Carolina en 1669 cuando Locke fue invitado a participar de la redacción del contenido normativo que tuteló los derechos absolutos de los esclavistas al prescribir que "todo hombre libre de Carolina debe tener absoluto poder sobre sus esclavos negros, cualquiera que sea la opinión y religión de estos." 14 Los efectos de esta normatividad pueden ser verificados años después cuando el economista inglés Malachy Postlethwayt, en 1744 defendió la Royal African Company, bajo el argumento de que "el comercio de negros y las consecuencias naturales que se derivan de ello se pueden valorar justamente como una inagotable reserva de riqueza y de poder naval para esta nación". ${ }^{15}$ En el siglo siguiente la perspectiva liberal del esclavismo ya estaba consolidada y el demócrata John Calhoun, vicepresidente de Estados Unidos (entre los años de 18291832) defendió la esclavitud como un "bien positivo" recurriendo a los argumentos presentes en el Segundo Tratado. ${ }^{16}$

13 Domenico Losurdo (2007). Contrahistoria del liberalismo . Barcelona, Editorial El Viejo Topo, p. 33 .

14 The Fundamental Constitutions of Carolina (1669).(One hundred and seven). Since charity obliges us to wish well to the souls of all men, and religion ought to alter nothing in any man's civil estate or right, it shall be lawful for slaves, as well as others, to enter themselves, and be of what church or profession any of them shall think best, and, therefore, be as fully members as any freeman. But yet no slave shall hereby be exempted from that civil dominion his master hath over him, but be in all things in the same state and condition he was In before. (One hundred and ten). Every freeman of Carolina shall have absolute power and authority over his negro slaves, of what opinion or religion soever.

15 Malachy Postlethwayt (1744) citado en Losurdo, 2007, p. 23.

${ }^{16}$ John Calhoun citado en Losurdo 2007, p. 16. 


\subsection{El modelo liberal de la trata de personas, de la esclavitud perpetua y colonización de la tierra}

La separación religiosa de los reinos europeos de Holanda, Inglaterra y Francia en el siglo XVI implicó, en el ámbito jurídico, el rompimiento con la jurisdicción del derecho canónico, que a través de las bulas Romanus Pontifex (1455) y Alejandrinas (1493) otorgó a los reinos ibéricos de Portugal y Castilla, el derecho de monopolio sobre el tráfico y esclavización de personas africanas, y sobre la expropiación y colonización de África y América respectivamente. ${ }^{17}$ Hasta entonces los reinos no ibéricos de la cristiandad participaban de estos infames negocios a través de licencias personales o, clandestinamente, con asaltos en alto mar, la toma de puertos y de áreas estrategias del dominio ibérico. Cesadas las guerras religiosas, la jurisdicción de la iglesia católica ya no alcanzaba los reinos de Francia, Holanda e Inglaterra que se proclamaron protestantes. Surgieron enseguida las compañías privadas de comercio y navegación dedicadas fundamentalmente al transporte y a la trata esclavista colonial hasta entonces monopolizadas por Portugal. El combate al monopolio ibérico fue realizado a través de esas compañías y de la implementación del libre comercio, tal como lo defendían las teorías del liberalismo.

Surgidas en la primera mitad del siglo XVII, las compañías de comercio y navegación llevaron el nombre Indias (aquellas dirigidas hacia África, Indias orientales, y aquellas hacia América, Indias occidentales). Tales compañías buscaban la libre competencia en el comercio de personas africanas que, vale recordar, era el más lucrativo, corrupto y cruel del periodo. En el marco del libre comercio, las compañías también realizaban el comercio de productos diversos tales como sedas de India, especias de oriente, tecnología naval de China. Esta competencia fue marcada por ataques constantes a embarcaciones portuguesas en alto mar y a la invasión de puertos en la costa Africana, en Asia y América. ${ }^{18}$ Sobre ese contexto, Adam Smith teorizó que el libre comercio permitiría el enriquecimiento y el poderío de los reinos pues "un comercio que se forma por medio de gratificaciones y monopolios [...] es poco

\footnotetext{
${ }_{17}$ Luis Weckmanns (1992). Constantino el Grande y Cristóbal Colón: estudio de la supremacía papal sobre islas (1091-1943). México, Fondo de Cultura Económica.

${ }^{18}$ Francisco Vidal Luna y Herbert S. Klein. (2010). Escravismo no Brasil. São Paulo, Edusp, Imprensa Oficial do Estado de São Paulo, p. 41-42
} 
ventajoso y perjudicial”. ${ }^{19}$ En el libro IV, capítulo VII, parte II, De las Causas de la prosperidad de las nuevas Colonias, Adam Smith defendió la necesidad de tener colonias para la prosperidad de los reinos europeos, bajo el argumento de la incapacidad de los pueblos nativos en aprovechar la riqueza natural de los territorios. En palabras del autor, "una colonia de cualquier nación civilizada que se establece en un vasto país, o en un territorio apenas habitado, y cuyos naturales ceden con facilidad su lugar a los nuevos colonos, adelanta con más rapidez en el camino de la riqueza que cualquiera otra sociedad." ${ }^{20}$ Asimismo el economista escocés utilizó los conceptos de civilizado en oposición al de bárbaras y salvajes para justificar la invasión, confisco y colonización de los territorios fuera de Europa;

aquellos colonos llevan consigo conocimientos en la agricultura y demás artes superiores a los que podrían adquirirse por pura práctica en el discurso de muchos años entre gentes bárbaras y salvajes [...] pero entre naciones bárbaras e incultas son, y han de ser necesariamente mucho más lentos los progresos que hagan las leyes y el gobierno bien ordenado, que los que pueden hacer las artes $\mathrm{y}$ las leyes en una sociedad de gentes en que se supone ya establecido un orden regular. ${ }^{21}$

La vasta circulación y prestigio otorgados a la obra de Smith, condujo a los Estados liberales de Europa a afianzar el proyecto colonial esclavista en diversas regiones del globo, con autoridad absoluta de los propietarios sobre sus dominios privados, ya sea tierra y personas, a punto que, a finales del siglo XVIII, los reinos protestantes liberales que entraron a competir con los ibéricos católicos, habían alcanzado gran acumulo de riqueza y prosperidad en sus territorios, gracias a saqueos, secuestros, tráfico y comercio de personas africanas, explotación hasta extinción de minerales y monocultivo de cana-de-azúcar, café, algodón, entre otros, en las colonias. La legitimidad de la autoridad absoluta del propietario esclavista puede ser encontrada en la teoría de John de Locke (1690), específicamente en el II Tratado de Gobierno Civil, donde el autor distinguió cinco tipos de autoridades legítimas: la autoridad política;

\footnotetext{
19 Smith Adam (1794). Investigación de la naturaleza y causas de la riqueza de las naciones. Valladolid, Ed. Oficina de la Viuda e Hijos de Santander, Tomo III, Libro IV. Capítulo VII. Parte II. De las Causas de la prosperidad de las nuevas Colonias, p. 2).

${ }^{20}$ Smith 1794, p. 135

${ }^{21}$ Smith 1794, p. 135
} 
la autoridad del padre sobre sus hijos (\$52-76); la autoridad del marido sobre la esposa (§82-83); la autoridad del amo sobre sus sirvientes (\$85) y la autoridad del propietario de esclavos sobre los mismos (\$22-24). La concepción lockeana de autoridad legítima fue adaptada a la legislación esclavista decimonónica de los países independientes de América, donde es posible verificar que los Estados independientes en América se garantizó el derecho de los propietarios esclavistas y se tuteló su poder absoluto y arbitrario dentro y fuera del dominio privado.

\subsection{El Estado soberano de Haití frente a los Estados liberales}

A partir de la legitimación de la esclavitud propuesta por Locke, las justificativas liberales a favor de la institución y de las prerrogativas de los propietarios esclavistas y colonialistas proliferaron entre los teóricos europeos, siendo Montesquieu autor de la noción de esclavitud natural y Tocqueville autor del concepto de esclavitud civilizatoria, ambos teorizando sobre una supuesta superioridad de los esclavistas sobre los esclavizados. Para mediados del siglo XVIII en el ámbito de la política liberal, "lo que existía era un sentimiento de superioridad cultural, pero no de la raza, es decir no era una superioridad biológicamente determinada." ${ }^{22}$ De acuerdo con el filósofo nigeriano Emmanuel Chuckwudi Eze la terminología racial (raza, progreso, civilización, salvaje, natural) para referirse a la especie humana, fue desarrollada por la filosofía alemana del siglo XVIII e inmediatamente comenzó a ser utilizada por las demás áreas del conocimiento, como la antropología y la medicina por ejemplo, que pasaron a estudiar el ser humano a partir del paradigma de la raza. Ezé analizó las teorías de los filósofos del final de siglo XVIII como Linneaus, Buffon, Hume, y sobre todo los argumentos de Kant, sobre las supuestas diferencias jerárquicas de las razas humanas. ${ }^{23}$

\footnotetext{
${ }^{22} \mathrm{~A}$ traducción es mía. "Regarding racial concepts hardly anyone (with one or two exceptions) tried to justify slavery by assuming the inferiority of blacks. What existed was the feeling of cultural superiority, but not of racial, i.e. biologically determined superiority". In.: Karin Schuller, (2001). "From liberalism to racism: German historians, journalists, and the Haitian revolution from the late eighteenth to the early twentieth centuries". In David P. Geggus (Ed.). The impact of the Haitian Revolution in the Atlantic World. University of South Carolina Press, (pgs. 23 - 43), p. 27.

23 Emmanuel Chukwudi Eze (2001) "El color de la razón: La idea de 'raza' en la antropología de Kant" En.: Enrique Dussel [et al] Capitalismo y geopolítica del conocimiento: el eurocentrismo y la filosofía de la liberación en el debate intelectual contemporáneo. Buenos Aires, Ediciones del signo.
} 
La emergencia del Estado soberano de Haití y la precisión de sus constituciones que prohibieron el régimen esclavista, la discriminación por color de piel y nacionalizaron la tierra, refutaban todas las concepciones racialistas que no podían concebir la generación autónoma de un Estado liberal por parte de africanos y sus descendientes. Esto impactó a tal punto, que inmediatamente el mundo liberal europeo y anglosajón se empeñó en elaborar disciplinas específicamente destinadas a la comprobación cartesiana de los presupuestos filosóficos de la jerarquía de las razas. ${ }^{24}$ Según sugiere Ezé, fue entonces cuando nació la antropología junto con un copioso marco teórico en diversas áreas del conocimiento que defendían una supuesta superioridad europea frente a las demás sociedades del planeta. ${ }^{25}$ De hecho, en adelante, los alemanes se valdrían del concepto raza para evaluar la revolución de Haití, y por consiguiente, la soberanía de ese Estado, la ciudadanía de sus habitantes y el tipo de relaciones se establecería con un Estado soberano Afrodescendiente no esclavista. ${ }^{26}$

Desde entonces, en los Estados liberales de América y Europa, los paradigmas de la raza se convirtieron en un locus explicativo para el diseño de políticas públicas, legislaciones y adjudicación de derechos y recursos diferenciados, según la clasificación de cada grupo social de la nación. Por otra parte, el triunfo de la Revolución de Santo Domingo - Haití fortaleció entre los esclavizados la lucha por la liberación de la esclavitud, en la misma proporción en que movilizó la defensiva de los propietarios esclavistas y del Estado liberal. El Estado de Carolina del Sur prohibió la entrada a su territorio de cualquier persona afrodescendiente proveniente de Santo Domingo o de las demás islas francesas en el Caribe, bajo el argumento de que podría difundir en el país esclavista las ideas de libertad y de igualdad social.

La revolución negra de Santo Domingo suscita una oleada de indignación en ambos países. "Un Estado negro en el archipiélago occidental - escribe "The Times" - es radicalmente incompatible con todo el sistema de la colonización europea". Y por tanto, "obviamente en esta zona, Europa recuperara la influencia y el do-

\footnotetext{
24 Karin Schuller, 2001

25 Emmanuel Chukwudi Eze (2001).

26 "This German image of Haiti changed during the second half of the nineteenth century, when advocates of a more anthropological way of historic reflection "discovered", so to speak, the role of race in history" Schuller, 2001, p. 31.
} 
minio que justamente reivindica, en virtud de la sabiduría superior, y de las dotes superiores de sus habitantes." Los Estados Unidos no solo se niegan a reconocer el país surgido de la revolución negra, sino que hacen todo lo posible por aislarlo, debilitarlo, demolerlo. ${ }^{27}$

Bajo premisas como estas, el temor y la indignación se expandieron por todo el mundo liberal esclavista que recurrió a la teoría racial del evolucionismo para combatir la soberanía del Estado de Haití y la libertad de las personas esclavizadas.

\subsection{Liberalismo y evolucionismo}

Desde sus inicios, el pensamiento liberal tuvo una propulsión hacia la evolución y el progreso de los Estados, pero fue en el siglo XIX cuando las reivindicaciones liberales de los derechos económicos y sociales, basadas en las teorías de Herbert Spencer y Charles Darwin, entre otros teóricos racialistas, tomaron reivindicaciones abiertamente racialistas. Spencer condenó cualquier tipo de interferencia estatal en la economía, bajo el argumento de que existiría una supuesta ley natural que eliminaría a las personas incapaces, para dar lugar al desarrollo de las personas capaces,

Con la finalidad de que pueda preparar la tierra para sus futuros habitantes sus descendientes, deben poseer un carácter ajustado para despejarlo de razas que ponen en peligro su vida, y razas que ocupen el espacio requerido para la humanidad. Por tanto, debe tener el deseo de matar, porque es la ley universal de la vida que a cada acto necesario se le sume su gratificación [...] en otras palabras, él debe ser lo que llamamos de salvaje, y debe ser abandonado para que adquiera aptitudes para la vida social hasta tanto la conquista de la tierra haga que la vida social sea posible. ${ }^{28}$

\footnotetext{
27 Losurdo 2007 p.180.

${ }^{28}$ La traducción es mía. "To the end that he may prepare the earth for its future inhabitants - his descendants, he must possess a character fitting him to clear it of races endangering his life, and races occupying the space required by mankind. Hence he must have desire to kill, for it is the universal law of life that to every needful act must attach a gratification, the desire for which may serve as a stimulus [...] in other words, he must be what we call a savage, and must be left to acquire fitness for social life as fast as the conquest of the earth renders social life possible". Spencer, Herbert (1851). Social statics: or the conditions essential to human happiness specified and the first of them developed . Editorial New York, Augustus M. Kelley, 1969, p.410-411.
} 
Con ideas como esta, el evolucionismo se desarrolló como el marco teóricoliberal para justificar las irregularidades cometidas por los Estados liberales. En Latinoamérica, los gobernantes liberales solían justificar sus políticas públicas en el paradigma racial de Spencer, que retomando el concepto de esclavitud civilizatoria de Tocquevile, afirmaba que los "salvajes" solo podrían llegar a la civilización a través de la esclavitud y que la tierra solo sería bien aprovechada a través de la colonización. Liberalismo y evolucionismo se convirtieron en teorías complementarias, pues, mientras el discurso evolucionista sostenía que el más adaptado sobreviviría a la existencia por ser capaz de innovar y crear riquezas a través de la explotación de la tierra y de la naturaleza (Spencer 1851), el discurso liberal, a través de la metáfora de la mano invisible, afirmaba que crear riqueza era un objetivo individual que beneficiaría el progreso social (Smith, 1794).

El paradigma racial solamente fue revaluado a mediados del siglo XX y se convirtió en un sofisma intelectual para todas las áreas del conocimiento que la utilizaron, incluyendo la genética y la medicina que han demostrado que las supuestas diferencias basadas en el nivel biológico de raza no son verificables científicamente, por tanto la raza no es una clasificación aplicable a los seres humanos. Sin embargo el sofisma de la raza sigue gozando de prestigio, y apoyo político y financiero, por consiguiente aún es capaz de servir de soporte a estereotipos alimentados por la miopía disciplinaria y los prejuicios históricos. ${ }^{29}$

\section{Los discursos abolicionistas liberales}

Como expresión del individualismo liberal, en el siglo XIX se desarrolló un discurso sobre los males que causaba el régimen de la esclavitud al esclavista y a la sociedad liberal, pues en los castigos, la crueldad y el maltrato hacia las personas esclavizadas, se ponían en evidencia los sentimientos más viles e inmorales del esclavista. Partiendo de la preocupación de no desarrollar una sociedad de verdugos insensibles, y no de la necesidad de otorgar derechos fundamentales a los seres humanos que yacían esclavizados, surgieron propuestas para abolir gradualmente la esclavitud,

\footnotetext{
${ }_{29}$ Tim Ingold, (2013). "Death of a paradigm”. In: Palsson, Gisli and Ingold, Tim. Biosocial becomings:
} integrating social and biological anthropology. New York, Cambridge University Press. 
siempre y cuando la indemnización pecuniaria a los esclavistas estuviera garantizada. Para justificar estas propuestas, la discriminación entre los dos grupos que integraban el régimen de la esclavitud estuvo basada en el sofisma racial desarrollado por la teoría evolucionista, el cual justificó prerrogativas favorables para los esclavistas que eran, en su mayoría, eurodescendientes en la misma medida en que restringió de derechos y la reparación a los afrodescendientes esclavizados.

\subsection{La abolición gradual y restricciones de derechos para las personas libertadas}

La abolición inmediata y sin indemnización de la esclavitud tal como fue realizada en Haití, fue tenazmente combatida por las élites liberales de Europa y América, quienes recurrieron a diferentes argumentos para postergar al máximo el mantenimiento de esa infame institución y extraer todo el lucro posible del proceso abolicionista. En Gran Bretaña, en el año de 1833, el teórico liberal y político cristianonuevo Benjamin Disraeli (hijo de padres judíos conversos al anglicanismo) criticó la abolición de la esclavitud y atribuyó la existencia del movimiento abolicionista al temor generado por la rebelión de 1831 en Jamaica y al debate en Inglaterra sobre las condiciones de trabajo, las cuales eran comparadas por los activistas ingleses con el régimen de la esclavitud y con la jerarquía racista. $3^{\circ}$ En Francia los proyectos de abolición total de la esclavitud sólo fueron considerados un año antes de la revolución de 1848. Hasta entonces se planteaba un abolicionismo gradual, como defendía el liberal Toquerville, "indudablemente es necesario proceder a la abolición de la esclavitud sólo con precaución y medida”, pues la libertad inmediata era concebida como libertad salvaje, debido a la concepción de que la "esclavitud liberal" elevaba el status del salvaje. ${ }^{11}$ Es oportuno recordar que el auge del liberalismo francés estuvo marcado por campañas militares neocoloniales como la toma de Argelia en 1830, de modo que, los discursos abolicionistas ocurrían en medio a la imposición colonialista francesa en territorios en África y Asia.

30 Simone Beate Borgstede (2011). "All is Race": Benjamin Disraeli on Race, Nation and Empire. Editor LIT Verlag Münster, p. 70.

${ }^{31}$ Alexi Tocqueville (1854) citado en Losurdo 2007, p.161 
51

En Estados Unidos los discursos de abolicionistas liberales tales como el de Guizot (1850) defendían el derecho de indemnización a los poseedores de una "propiedad legítima" y la preocupación con la inexistencia de fondos que garantizasen esta operación. $3^{2}$ Vale la pena destacar que los discursos liberales, ya sea las justificativas de la esclavitud o de la abolición, ninguno tuvo en cuenta los derechos humanos de las personas esclavistas, o de qué manera esas personas irían a integrarse a la sociedad. El liberal Tocqueville inclusive justificó la restricción del acceso a la tierra a las personas egresas de la esclavitud bajo el siguiente argumento;

Prohibiendo momentáneamente a los negros la posesión de la tierra, ¿Qué se hace? Se les coloca artificialmente en la posición en que se halla de manera natural el trabajador europeo. En realidad no existe tiranía, y el hombre al que se le impone solamente este obstáculo al momento de su salida de la esclavitud, no parece que tenga derecho a lamentarse. 33

Por lo general en los Estados liberales las personas egresas de la esclavitud en América y los siervos en Europa, fueron excluidos del derecho a poseer la tierra, a la educación, de ejercer determinadas profesiones, de acceder a la justicia, testificar en tribunales, hacer parte del consejo de jueces. En Irlanda, por ejemplo, la colonización inglesa trató de impedir el acceso de la población nativa a la educación liberal y a la justicia. La legislación colonial inglesa hacia los irlandeses era deliberadamente restricta a la explotación de la "propiedad e industria [...], mantenerlos en condiciones de pobreza, destruir en ellos cualquier germen de iniciativa empresarial, degradarlos al rango de una casta servil que no abrigue nunca la esperanza de elevarse al nivel de sus opresores"34. En Estados Unidos, bajo la Ley de prohibición de mestizaje las personas afrodescendientes fueron excluidas del derecho a la libre locomoción y de la libertad para contraer matrimonios. 35 Mientras que en Latinoamérica las leyes eugenésicas regularon los matrimonios, la natalidad y los tratamientos médicos de las

\footnotetext{
$3^{2}$ François Guizot (1869) citado en Losurdo 2007, p.161.

33 Alexi Tocqueville (1854) citado en Losurdo 2007 p. 228.

34 Losurdo 2007, p.122

35 Losurdo 2007, p.109
} 
gestantes. ${ }^{6}$ Por otra parte en la historia del derecho podemos observar que el fenómeno del esclavismo liberal originó una legislación penal exclusiva para las personas esclavizadas, basadas tanto en el estatuto jurídico del esclavo como en la concepción de raza:

aunque la legislación penal del liberalismo ya fuera influenciada por las concepciones iluministas sobre la sociedad, el crimen y las penas, como las de Beccaria y Feuerbach - la condición de esclavo era agravante de la penalidad empeorando jurídicamente una situación que, de hecho, ya era desigual. 37

El mantenimiento de la esclavitud en el orden político liberal dejó la marca de la ambigüedad del sistema jurídico relativo a la institución, así como la paradoja de la regulación donde las personas esclavizadas eran simultáneamente sujeto en el derecho penal y objeto en el derecho privado. En una perspectiva que postula la incompatibilidad entre liberalismo y esclavitud, la historiadora brasileña Emilia Viotti señaló que la principal limitación del liberalismo fue su peculiar convivencia con la institución de la esclavitud, evidenció que en la práctica los principios liberales eran extremamente débiles.

[...] formulas representativas de gobierno, los discursos afirmando la soberanía del pueblo, defendiendo la igualdad y la libertad como derechos inalienables e imprescriptibles del ser humano, cuando en la realidad, se pretendía mantener esclavizada buena parte de la población y alienada de la vida política a otra parte. $3^{8}$

La autora desarrolló esta idea para el caso de Brasil, demostrando que el liberalismo asumió diferentes facetas en el mismo contexto esclavista para finalmente

${ }^{36}$ Eduardo A. Sambrini (2004). "Impedimentos de carácter eugenésico para contraer matrimonio". Derechos y Eugenesia. Buenos Aires, Educa.

37 Arno Wehling (2006). "O escravo ante a lei civil e a lei penal no Império (1822-1871)" En: Carlos Wolkmer (org). Fundamentos de História de Direito. Belo Horizonte, 3ed, Editora Del Rey, p.339. Traducción es mía.

${ }^{38}$ Emília Viotti da Costa (1985). Da Monarquia à República: Momentos decisivos. $7^{\mathrm{a}}$ ed. São Paulo, Unesp, 1999, p.28-29 
imponerse como un liberalismo de tendencia conservadora, llevado a cabo por oligarquías hegemónicas, antidemocráticas, arraigadas a las prácticas del "favor, del clientelismo y de la padrinaje". 39

Es oportuno señalar que los grupos sociales oprimidos, esclavizados y discriminados de derechos se apropiaron del discurso de libertad e igualdad del liberalismo conformando un sector de liberales populares que hacían frente al liberalismo de las oligarquías de terratenientes, esclavistas y clientelistas. En esta misma línea de análisis, Alfredo Bosi planteó que la esclavitud convivió por tanto entre dos liberalismos expresados en diferentes y opuestas concepciones: el liberalismo esclavista y el liberalismo antiesclavista, presente no solamente en Brasil sino en los demás países liberales de Europa y América. ${ }^{\circ 0}$ Mientras la tendencia liberal esclavista se basaba en la teoría lockeana donde la institución de la esclavitud no vulneraba el derecho natural sino era tan legítima cuanto la propiedad privada (Locke 1690, cap.5 de la propiedad, §85); la tendencia liberal antiesclavista sustentaba, desde mediados del siglo XVIII, que la esclavitud era el principal impedimento para el progreso humano. ${ }^{41}$

\subsection{Las leyes de abolición de la esclavitud en Brasil y Colombia}

En 1823 el político brasileño José Bonifacio presentó a la Asamblea Constituyente del imperio de Brasil un proyecto de ley que proponía la prohibición del sistema esclavista y la transición para el régimen de libertad que contemplaba tanto la indemnización pecuniaria para los propietarios esclavistas (art.7) como la compensación para las personas libertadas a través de la distribución de tierras y herramientas necesarias para el trabajo rural (art.27). ${ }^{2} \mathrm{El}$ proyecto no fue aceptado por los legisladores y solamente sesenta y cinco años después la esclavitud fue prohibida en el país

\footnotetext{
39 Viotti da Costa, 1985 p. 127.

40 Alfredo Bosi, (1992). Dialética da colonização. 2. ed. São Paulo: Cia. das Letras, p.195.

${ }^{41}$ David Brion Davis (1986). Slavery and human progress. New York, Oxford University Press.

${ }^{42}$ Representação de José Bonifácio Assembleia Gera Constituinte Legislativa do Império do Brasil (1823). A Abolição no Parlamento (1823-1888) 65 anos de lutas. Brasília, Senado Federal Secretaria Especial de Editoração 2012, volume I, pag. 31-47
} 
y omitió cualquier tipo de compensación para las personas afectadas por la esclavitud. En cuanto a la indemnización para los esclavistas, esta fue garantizada por las leyes de abolición gradual como la Ley 2040 de $1871^{43}$ conocida como ley del vientre libre y la Ley 3270 de $1885^{44}$ conocida como ley los sexagenarios. Como prescrito en estas leyes, las personas beneficiadas deberían pagar con trabajo la indemnización a los esclavistas, como condición para la liberación. El tiempo de trabajo varió entre 18 y 25 años para los nacidos bajos la ley del vientre libre y 6 años para los sexagenarios. En cuanto a la indemnización pecuniaria, ésta fue garantizada por los fondos de emancipación que fueron creados en el artículo $3^{\circ}$ de la ley del vientre libre. Se configuraba así un sistema de recaudación creado por el gobierno imperial, proveniente de la tasa de matrícula de las personas esclavizadas, impuestos, multas, loterías y donaciones.

La abolición definitiva de la esclavitud fue dictada por la Ley 3353 de 1888 y no previó ningún tipo de indemnización para ninguna de las partes. Sin embargo bajo la influencia de las teorías liberales y de las experiencias de los países de Hispanoamérica y del Caribe, en el mismo mes en que fue proclamada la ley abolicionista, empezaron a tramitarse en el senado del gobierno imperial, dos proyectos (Proyecto $\mathrm{n}^{\mathrm{0}} 10$ de 1888; Proyecto $\mathrm{C}$ de 1888 ) que proponían la indemnización a los propietarios esclavistas por parte del Estado, el cual seguía el mismo modelo inglés de deuda pública. Los referidos proyectos no llegaron a ser votados pues, por orden del ministro de la hacienda Rui Barbosa (Decisión de 14.12.1890), fueron incineradas todas las matrículas de esclavos que eran los registros referentes a la propiedad esclava existente en el país y que servirían de referencia para el monto indemnizatorio a los propietarios esclavistas. Con esta medida el gobierno republicano brasileño (1889) fue eximido del pago indemnizatorio a los esclavistas, por falta de documento probatorio. 45

En Colombia la burocracia estatal encargada de la operatividad de los fondos de manumisión fue denominada junta de manumisión y era compuesta por jueces,

43 Ley 2040 de 1871. En. A Abolição no Parlamento (1823-1888) 65 anos de lutas. Brasília, Senado Federal Secretaria Especial de Editoração 2012, volume I, pag. 564

44 Ley 3270 de 1885. En. A Abolição no Parlamento (1884-1888) 65 anos de lutas. Brasília, Senado Federal Secretaria Especial de Editoração 2012, volume II, pag.281

45 A Abolição no Parlamento (1884-1888) 65 anos de lutas. Brasília, Senado Federal Secretaria Especial de Editoração 2012, volume II, pag. 515-528. 
miembros del clero y funcionarios públicos, que determinaban cuales personas esclavizadas serían manumitidas y el valor a ser pago por el fondo al propietario esclavista. Cuando el valor del fondo era insuficiente, las personas esclavizadas tenían que completar la suma para ser libertadas; o también el esclavista podría aceptar recibir un valor menor. Estos fondos surgieron simultáneos a la ley de vientres de $1821 \mathrm{y}$ fueron considerados sagrados en la Ley de 21 de mayo de 1851 sobre la libertad de esclavos. En la referida ley de los 19 artículos que la conformaron, solamente los artículos 4 y el 14 hacían expresa referencia a la libertad de los esclavizados, los 17 artículos restantes definieron la forma de pago de los fondos, identificados como deuda de primera clase para aquellos generados antes de 1851, y deuda de segunda clase para aquellos generados después de la ley. ${ }^{6}$ Todos los fondos de manumisión fueron amortizados por el gobierno hasta el año de 1866 como deuda pública de manumisión y, fueron parte de la deuda interna flotante del Estado Colombiano47.

\subsection{La injusticia histórica del liberalismo}

A partir del contexto analizado, es posible sugerir que la omisión de las leyes abolicionistas y las restricciones de derechos de las personas egresas de la esclavitud, hayan conllevado a contextos sociales de extrema desigualdad resultando en injusticias históricas cometidas por el Estado liberal a través de la vulneración de los derechos humanos. Asimismo, las leyes indemnizatorias constituyen una evidencia de la aplicación del tratamiento jurídico diferenciado y discriminatorio del derecho liberal, con consecuencias hasta los días actuales en el sistema jurídico, especialmente en el derecho penal tal como señala el jurista argentino Eugenio Zafaroni, "[...] la discriminación en el ejercicio del poder punitivo es una constante derivada de su selectividad estructural." ${ }^{8}$ Es oportuno recordar que las personas afrodescendientes y originarias del continente, bajo la égida de las teorías raciales decimonónicas, fueron vulneradas en todos sus derechos y aún lo son en los días actuales, por el racismo

\footnotetext{
${ }^{46}$ Ley sobre Libertad de Esclavos (mayo 21 de 1851). Archivo General de la Nación, fondo Negros y Esclavos, Legislación http://negrosyesclavos.archivogeneral.gov.co/portal/apps/php/legislacion.kwe

47 Villaveces Niño, Juanita. "Formación de la deuda pública en Colombia (1821-1873)." Facultad de Economía. Bogotá: Editorial Universidad del Rosario, 2007. Serie Documentos. Borradores de Investigación; 84. http://www.urosario.edu.co/economia/documentos/pdf/bi84.pdf

48 Eugenio R. Zaffaroni (2006). El enemigo en el derecho penal. Bogotá, Editorial Ibañez, p.105.
} 
creado por las teorías raciales europeas y aplicado por los Estados que recurrieron a estas teorías para elaboración de sus políticas, leyes y su sistema jurídico,

En efecto, existe un nexo profundo entre democracia e igualdad y, a la inversa, entre desigualdad en los derechos y racismo. Del mismo modo que la igualdad en derechos genera el sentido de la igualdad basada en el respeto del otro como igual, la desigualdad en los derechos genera la imagen del otro como desigual, o sea, inferior en el plano antropológico, precisamente por ser inferior en el plano jurídico. 49

En la historia de la esclavitud y la abolición, podemos verificar que las personas esclavizadas además de no haber recibido ningún tipo de indemnización o reparación por los daños causados por la esclavitud, entraron con derechos restringidos en la sociedad de los libres, a punto que los efectos de la normatividad basada en el sofisma racial llegan hasta los días actuales evidenciando una injusticia histórica, establecida y documentada, y por tanto del deber del Estad reparar esas injusticias.

Recordemos que las teorías del liberalismo del siglo XVIII y XIX desarrollaron la doctrina de la ley como única fuente de derecho, irrefutable e incontrovertible, con total confianza por parte del poder legislativo, en detrimento del poder judicial, que se limitó a un ejercicio exegético y literal de las normas legisladas. De ese modo, la injusticia de la ley y la limitación al legislador se convirtieron en postulados incuestionables, que compelían a los demás poderes, ejecutivo y judiciario y a toda ciudadanía, al estricto cumplimiento de la ley. En este contexto, sugerimos que la responsabilización por el esclavismo liberal así como la omisión legislativa y discriminatoria en que incurrieron las leyes de abolición de la esclavitud, es una pendencia que tienen todos los Estados liberales con los descendientes de la diáspora africana promovida por la trata de personas de este continente y su posterior esclavización en Europa y América.

49 Ferrajoli, 1999, p.58. 


\section{Conclusiones}

La concepción racista acerca de la humanidad permitió el mantenimiento de la trata y de la esclavitud de personas en el contexto de los Estados liberales que proclamaron los derechos humanos y las libertades fundamentales. Actualmente estas prácticas son consideradas como crímenes de lesa humanidad, dada la extensión del daño causado y la larga duración de sus consecuencias.

Crímenes de lesa Humanidad serían todas aquellas violaciones gravísimas del derecho internacional que lesionan a la humanidad, aunque materialmente se hayan afectado únicamente los derechos de un grupo de personas. Estas infracciones graves surgen de acciones $u$ omisiones imputables al individuo, generando responsabilidad internacional tanto para el autor como para el Estado que debió actuar en prevención y represión. Definidos de esta forma, estarían comprendidos todos aquellos ilícitos de derecho internacional, por ejemplo, los crímenes de guerra, el genocidio, la agresión, la trata de personas, el narcotráfico, la esclavitud, la tortura, entre oros" 50

Aunque sea consenso en las constituciones actuales, los acuerdos internacionales, el derecho interno de los Estados constitucionales y el derecho internacional que la trata de personas y la esclavitud constituyen un crimen de lesa humidad y una injusticia histórica de responsabilidad del Estado, la debida reparación a la población Afrodescendiente aún es tema de debate y polémica.

\section{Bibliografía}

Abolição no Parlamento (1884-1888) 65 anos de lutas. Brasília, Senado Federal Secretaria Especial de Editoração 2012, volume II.

Adam Smith (1794). Investigación de la naturaleza y causas de la riqueza de las naciones. Valladolid, Ed. Oficina de la Viuda e Hijos de Santander, Tomo III, Libro IV. Capítulo VII. Parte II. De las Causas de la prosperidad de las nuevas Colonias.

\footnotetext{
50 Maria Cristina Rodríguez, (2006). "Crímenes de lesa Humanidad”. Cuadernos de Derecho Inter-
} nacional, $\mathrm{n}^{\circ}$ 2, p. 143-192. http://www.corteidh.or.cr/tablas/r29223.pdf 
Alfonso X, "El Sabio”. Las siete partidas (1256-1265). Selección, prólogos y notas de Francisco López Estrada y María López García-Berdoy. Madrid: Editorial Castalia, 1992.

Alfredo Bosi, (1992). Dialética da colonização. 2. ed. São Paulo: Cia. das Letras.

Arno Wehling (2006). "O escravo ante a lei civil e a lei penal no Império (1822-1871)" En: Carlos Wolkmer (org). Fundamentos de História de Direito. Belo Horizonte, 3ed, Editora Del Rey.

Bartolomé de las Casas (1567). Brevisima relacion de la destruccion de Africa: preludio de la Destrucción de Indias: primera defensa de los guanches y negros contra su esclavización. Editorial San Esteban, 1989.

B. Macintyre, (2010), "The fault line in Haiti runs straight to France". The Sunday Times, 21.

David Brion Davis (1986). Slavery and human progress. New York, Oxford University Press.

Domenico Losurdo (2007). Contrahistoria del liberalismo. Barcelona, Editorial El Viejo Topo.

Eduardo A. Sambrini (2004). "Impedimentos de carácter eugenésico para contraer matrimonio". Derecho y Eugenesia. Buenos Aires, Educa.

Emília Viotti da Costa (1985). Da Monarquia à República: Momentos decisivos. $7^{\mathrm{a}}$ ed. São Paulo, Unesp, 1999.

Emmanuel Chukwudi Eze (2001) "El color de la razón: La idea de 'raza' en la antropología de Kant" En.: Enrique Dussel [et al] Capitalismo y geopolítica del conocimiento: el eurocentrismo y la filosofía de la liberación en el debate intelectual contemporáneo. Buenos Aires, Ediciones del signo.

Eric E Williams (1944). Capitalismo y esclavitud. Habana, Editorial La Habana, Ciencias Sociales, 1964.

Eugenio R. Zaffaroni (2006). El enemigo en el derecho penal. Bogotá, Editorial Ibañez. 
Ferrajoli, Luigi (1999). Derechos y garantías. La ley del más débil. Madrid, Editorial Trotta.

Francisco Vidal Luna y Herbert S. Klein. (2010). Escravismo no Brasil. São Paulo, Edusp, Imprensa Oficial do Estado de São Paulo.

George Reid Andrews, (2007), "Las guerras por la libertad 1810-189o". En Afro-Latinoamérica 1800-200o. Madrid, Iberoamericana, Frankfurt am Main, Vervuert.

Herbert Spencer, (1851). Social statics: or the conditions essential to human happiness specified and the first of them developed. Editorial New York, Augustus M. Kelley, 1969.

H. M. Beckles, (1991). "An Unnatural and Dangerous Independence. The Haitian Revolution and the Political Sociology of Caribbean Slavery". The Journal of Caribbean History, 25(1), 160

John Locke (1690). Segundo Tratado sobre el Gobierno Civil. Un ensayo acerca del verdadero origen, alcance y fin del Gobierno Civil. London, Aronsham Churchill, at the black swan in Ave-Mary-Lane, by Amen-Corner.

Juanita Villaveces Niño, "Formación de la deuda pública en Colombia (1821-1873)." Facultad de Economía. Bogotá: Editorial Universidad del Rosario, 2007. Serie Documentos. Borradores de Investigación; 84. http://www.urosario.edu.co/economia/documentos/pdf/bi84.pdf

Karin Schuller,(2001). "From liberalism to racism: German historians, journalists, and the Haitian revolution from the late eighteenth to the early twentieth centuries". In David P. Geggus (Ed.). The impact of the Haitian Revolution in the Atlantic World. University of South Carolina Press, (pgs. 23 - 43).

Ley 2040 de 1871. En. A Abolição no Parlamento (1823-1888) 65 anos de lutas. Brasília, Senado Federal Secretaria Especial de Editoração 2012, volume I.

Ley 3270 de 1885. En. A Abolição no Parlamento (1884-1888) 65 anos de lutas. Brasília, Senado Federal Secretaria Especial de Editoração 2012, volume II.

Ley sobre Libertad de Esclavos (mayo 21 de 1851). Archivo General de la Nación, fondo Negros y Esclavos, 
Legislación

http://negrosyesclavos.archivogeneral.gov.co/portal/apps/php/legislacion.kwe

Luis Weckmanns (1992). Constantino el Grande y Cristóbal Colón: estudio de la supremacía papal sobre islas (1091-1943). México, Fondo de Cultura Económica.

Maria Cristina Rodríguez, (2006). "Crímenes de lesa Humanidad”. Cuadernos de Derecho Internacional, ${ }^{\circ}$ 2, p. 143-192.

Representação de José Bonifácio Assembleia Gera Constituinte Legislativa do Império do Brasil (1823). A Abolição no Parlamento (1823-1888) 65 anos de lutas. Brasília, Senado Federal Secretaria Especial de Editoração 2012, volume I, pag. 31-47

Saunders, A.C.C.M. (1994). Historia social dos escravos e libertos negros em Portugal (1441-1555.). Lisboa, Imprensa Nacional Casa da Moeda, 1994.

Simone Beate Borgstede (2011). "All is Race": Benjamin Disraeli on Race, Nation and Empire. Editor LIT Verlag Münster.

Tim Ingold, (2013). "Death of a paradigm". In: Palsson, Gisli and Ingold, Tim. Biosocial becomings: integrating social and biological anthropology. New York, Cambridge University Press. 